\title{
Pharmacy Education Virtual Conference Proceedings 2021: The digital switch
}

\author{
Manchester, United Kingdom
}

Oral Presentation

\author{
Student pharmacists' perceptions of facilitator \\ involvement in competency-based assessments \\ within practice-based experiential learning \\ Sabrina Anne Jacob ${ }^{1}$ (D) , Ailsa Power ${ }^{2}$ (D), \\ Jane Portlock ${ }^{3}$, Tesnime Jebara 4 (D), \\ Scott Cunningham ${ }^{4}$ Anne Boyter ${ }^{*}$ (D) \\ ${ }^{1}$ Strathclyde Institute of Pharmacy and Biomedical Sciences, \\ University of Strathclyde \\ ${ }^{2}$ NHS Education for Scotland \\ ${ }^{3}$ School of Life Sciences, University of Sussex \\ ${ }^{4}$ Robert Gordon University \\ *Presenting author: anne.boyter@strath.ac.uk
}

Keywords: Competency-based assessment, Experiential learning, M.Pharm., Pharmacy, Student pharmacist

Background: The Pharmacy additional cost of teaching (ACTp) (Wright, 2019) evaluation project seeks to explore the practicality of experiential learning (EL) facilitators undertaking competency-based assessments of students during EL.

Aim: To obtain students' perceptions of placement facilitators assessing students during their EL.

Method: Undergraduate M. Pharm. students from Robert Gordon University (RGU) and the University of Strathclyde (UoS) were surveyed using an online questionnaire. It contained only one open-ended question which sought to capture their thoughts on facilitators assessing them during EL. Thematic content analysis was undertaken on the responses received.
Results: Eighty-two responses were received; 13 incomplete responses; 69 included: 42 UoS, 27 RGU. Favourable responses were received from 34 (49\%) with regard to facilitators assessing students. Thematic content analysis revealed five key themes: 1) Current perceptions and expectations of EL placements; 2) Perceived benefits of facilitators assessing students; 3 ) Perceived drawbacks of facilitators assessing students; 4) Potential barriers and challenges in facilitators assessing students, and 5) Suggestions and concerns. Students were concerned about the extra stress and the impact of the assessment on their overall grades; however, they acknowledged the benefits of being assessed and receiving feedback from trained practitioners in the real-world setting who would be engaged in the students' EL. Variability in marking as well as facilitators' lack of experience with assessments, were also highlighted, with suggestions that facilitators should be trained in assessment and equipped with information on students' level of knowledge. Students also thought that quality assurance measures should also be adopted to ensure standardisation in marking.

Discussion: Students were on the whole ambivalent about the suggested approach, with concerns raised about the impact of the assessments as well as the capability of facilitators to assess them. To allay these anxieties, students should be involved as co-creators in the design and structure of the assessment components.

\section{Reference}

Wright, S. (2019) Scottish government invests $f 2.85 \mathrm{~m}$ to expand experiential learning of student pharmacists to new settings. The Pharmaceutical Journal, March, Online. http://doi.org/10.1211/PJ.2019.20206248 


\author{
Exploring students' reasons for choosing to \\ study pharmacy \\ Catherine Langran* (i), Chantelle Igwe \\ University of Reading, Berkshire, United Kingdom \\ *Presenting author: c.a.langran@reading.ac.uk
}

Keywords: Careers, M. Pharm., Outreach, Universities and Colleges Admissions Service (UCAS)

Background: Recent years have seen an overall decline in pharmacy applications at the United Kingdom (UK) universities (Andalo \& Wickware, 2018).

Aim: To explore what influences students' choice of studying pharmacy and choice of university.

Method: An online survey was distributed to undergraduate pharmacy students at the University of Reading. One-to-one interviews were undertaken with nine volunteer students. Inductive analysis of interviews was undertaken with intercoder reliability.

Results: The survey response rate was $21 \%(n=140)$. Students rated the importance of factors involved in their decision to study pharmacy. The interviews also explained reasons for choosing pharmacy: "Coming from an African household, it's kind of important to pick a job that is professional. Pick a job that gives you a good reputation, something they're proud of." Students reported being very familiar (26\%), partially familiar $(53 \%)$ and unfamiliar $(21 \%)$ with the role of a pharmacist prior to choosing to start their degree. "I don't think enough people understand what pharmacists do... what the job can lead to, I think the best way that people would start to want to apply more for pharmacy is if they actually knew what we did." The most commonly used online sources of information were university websites $(70 \%)$ and YouTube (34\%), compared to Facebook (2\%), General Pharmaceutical Council (11\%), and Royal Pharmaceutical Society (9\%) websites. "I went on YouTube, and the 'day in the life as a pharmacy student' vlogs were the best things". The most important factor when choosing which university was the employment rates after graduation, location of university and entry grade requirements.

Discussion: This study identified a need to increase the promotion of the role of pharmacists and employability, especially on university web pages and in YouTube vlogs. The study is limited by the response rate and by being conducted in one school of pharmacy.

\section{Reference}

Andalo, D., \& Wickware, C. (2018). Why are pharmacy schools struggling to fill places? The Pharmaceutical Journal, 301, 7919. https://doi.org./10.1211/PJ.2018.20205736

\section{A qualitative study of students' experiences being peer teachers of the NICE evidence search}

\author{
M. McCorriston ${ }^{1}$, M-C. Kearney ${ }^{1}$, A. Weist ${ }^{2}$, L. Edgar ${ }^{2}$, \\ J. Jefferies ${ }^{2}$, K. Burnett ${ }^{3}$, S. Haughey ${ }^{1}$, B. Girvin ${ }^{1 *}$ \\ ${ }^{1}$ School of Pharmacy, Queen's University Belfast, Northern Ireland \\ ${ }^{2}$ National Institute for Health and Care Excellence (NICE) \\ ${ }^{3}$ School of Pharmacy and Pharmaceutical Sciences, Ulster \\ University, Northern Ireland \\ *Presenting author: b.girvin@qub.ac.uk
}

Keywords: National Institute for Health and Care Excellence (NICE) Evidence search, NICE Student Champion, Peer teaching

Background: Pharmacy students must be able to support the learning and development of others (GPhC, 2021), of which peer teaching provides an opportunity to do this. In 2020, six M. Pharm. students from Queen's University Belfast (QUB) and three from the Ulster University (UU) were trained as National Institute for Health and Care Excellence (NICE) student champions on how to use NICE evidence search (NICE, 2021) and then cascaded the training to their peers.

Aim: To gain feedback from students on their experiences of being peer teachers as part of the NICE student champion scheme

Method: Following ethical approval, all nine student champions were invited to partake in semi-structured interviews on Microsoft teams. Interviews were audio or video recorded, transcribed verbatim and analysed thematically.

Results: Seven students took part. Student experiences were very positive, with themes and sub-themes shown in Table I.

Table I: Themes and sample quotations from the NICE student champion interviews

\begin{tabular}{l}
\hline Themes \\
\hline Theme 1: Motivation \\
1.1 Employability: \\
"It was just something unusual to talk about ... on my CV" [SC1] \\
1.2 Opportunity: \\
"It can allow me to have early engagement with NICE." [SC6] \\
Theme 2: Preparedness \\
2.1 For Professional practice: \\
"Pharmacists ......are always doing some form of teaching- whether \\
that's teaching your patients .......or other pharmacists." [SC7] \\
2.2 Practice for Online Sessions: \\
"Having that practice was really good." [SC2] \\
2.3 NICE Training: \\
"It really prepared you on how to...give the content, and what way \\
to deliver the content." [SC3]
\end{tabular}




\begin{tabular}{l}
\hline Themes \\
\hline Theme 3: Transferrable skills development \\
3.1 Communication Skills \\
"I should be able to communicate with people better" [SC5] \\
3.2 Teaching Skills \\
"It's particularly applicable for when you're counselling a patient, \\
you're teaching them how to use .. their inhaler." [SC3] \\
Theme 4: Learning medium \\
4.1 Online versus Face-to-face: \\
"It would have been nice to do it face-to-face". [SC3] \\
4.2 Continuity of platforms: \\
"It would have been better if they [NICE] used Microsoft Teams \\
because that's what we used when we were doing the cascade \\
sessions." [SC1] \\
4.3 Interaction and Engagement: \\
"We used Slido for a quiz...it kept people engaged." [SC1] \\
Theme 5: Peer teaching \\
5.1 Mutual learning environment: \\
"We're learning and our peers are learning, so it's... a mutual \\
learning environment." [SC4] \\
5.2 Future perspectives: \\
"Everyone should be given the chance to do this" [SC4] \\
*SC: Student Champion \\
\hline the
\end{tabular}

Discussion: Students reported many advantages to peer teaching, and the established structure of the teaching activity and training provided by NICE will help inform further peer teaching activities within the M. Pharm. programme.

\section{Reference}

General Pharmaceutical Council (2021). Standards for the initial education and training of pharmacists. London, GPhC. Available at: https://www.pharmacyregulation.org/sites/default/files/document/ standards-for-the-initial-education-and-training-of-pharmacistsjanuary-2021_0.pdf

National Institute for Health Care Excellence (2021). NICE Student Champions. Available at: https://www.nice.org.uk/getinvolved/student-champions

\section{Supporting and educating pharmacists in critical care during the COVID-19 pandemic: An exploratory study}

Shivani Garg ${ }^{1 *}$, Claire Anderson ${ }^{1}$, Vincent $\mathrm{Ng}^{2}$

${ }^{1}$ University of Nottingham, Nottingham, United Kingdom

${ }^{2}$ The Royal Pharmaceutical Society, 66-68 East Smithfield, London, United Kingdom

*Presenting author: paysg5@nottingham.ac.uk
Background: The coronavirus disease (COVID-19) highlighted the prominent role pharmacists have in supporting public health (Fauci, Lane and Redfield, 2020). In May 2020, the Royal Pharmaceutical Society (RPS) published online training resources in a bid to guide pharmacists within their deployment role (Critical Care Training RPS, 2020). This project explored the usage and views of pharmacists using the RPS COVID-19 training resources in critical care.

Aim: To explore the role of supporting and educating pharmacists in critical care during the COVID-19 pandemic.

Method: A mixed-methods approach was undertaken and delivered in two phases. Phase one constituted a survey to capture views on the usefulness and value of RPS education resources. The questionnaire was available for three weeks via Qualtrics. Analysis of survey data was conducted in Excel. In phase two, follow-up semi-structured video call interviews were conducted with survey participants to explore deeper perceptions. Interviews were transcribed verbatim and thematically analysed.

Results: A total of 84 survey responses were received; $80 \%$ $(n=67)$ of respondents were pharmacists deployed to critical care. $52.2 \%(n=35 / 67)$ utilised RPS resources to upskill and improve their knowledge during the pandemic. $86 \%$ $(n=30 / 35)$ who accessed the resources worked in critical care for more than 21 hours a week. The survey and interviews $(n=4)$ demonstrated the value the resources had within pharmacists' training. A senior critical care pharmacist stated, "there was an improvement in confidence and competence". It seemed that lack of time and awareness led to the pharmacists ( $n=32 / 67)$ not accessing the resources.

Discussion: Royal Pharmaceutical Society COVID-19 education and training resources had a significant benefit on pharmacists' confidence working in a critical care environment. Engagement with resources was relatively low, which can be boosted by increasing awareness and usefulness of resources. The understanding of COVID-19 is constantly developing; therefore, it is imperative to regularly update and improve resources for pharmacists working on the frontline.

\section{Reference}

Fauci, A., Lane, H. \& Redfield, R. (2020). Covid-19 - Navigating the Uncharted. New England Journal of Medicine, 382(13), 1268-1269. https://doi.org/10.1056/NEJMe2002387

Royal Pharmaceutical Society (2020). COVID-19 Critical Care Training Resource. Available at:

https://www.rpharms.com/resources/pharmacy-

guides/coronavirus-covid-19/clinical-resources-during-covid19/upskilling-during-covid-19/critical-care-

training\#acknowledgements

Keywords: COVID-19, Critical Care, Pandemic, Pharmacy

Education, Royal Pharmaceutical Society 


\section{Pharmacy students' views on the impact of COVID-19 on their health and academic experience}

\author{
Jenny Morrow*, Maurice Hall ${ }^{(D)}$, Lezley-Anne Hanna (D) \\ Kingdom Queen's University Belfast, United Kingdom \\ *Presenting author: jmorrow28@qub.ac.uk
}

Keywords: COVID-19, Pharmacy students, Questionnaire, Views

Background: The COVID-19 pandemic has had a significant global impact, including on higher education and the student experience (Office for National Statistics, 2021). From September 2020 in Queen's University Belfast School of Pharmacy, the majority of teaching and assessments were delivered online, but several additional measures were introduced to support students (including weekly online discussion sessions with staff and more one-to-one interactions with personal tutors).

Aim: To determine Queen's University Belfast pharmacy students' views on the extent to which the COVID-19 pandemic had affected their health and academic outcomes.

Method: Following ethical approval and an email invitation to participate, data about the pandemic and student experience were collected in January 2021 via an online questionnaire (from consenting first and final year students). Data analysis took the form of descriptive and inferential statistics with non-parametric tests used to determine whether there were differences in responses by gender and year group. Significance was set at $p<0.05$.

Results: A response rate of $44.4 \%$ (104/234) was obtained; $77.9 \%(81 / 104)$ respondents were female, and $22.1 \%$ $(23 / 104)$ were male. Many $(70.2 \%)$ deemed their mental health had declined as a result of the pandemic. Only $12.5 \%$ reported the pandemic had caused them to increase their alcohol intake. Most (88.5\%) were worried about academic outcomes and $47.2 \%$ considered they did not have sufficient support from academic staff teaching on the M. Pharm. degree programme. While $58.7 \%$ felt concerned about contracting the virus on campus, female students were more likely to consider there should have been more face-to-face teaching from September to December 2020 (43.2\% females versus $17.3 \%$ males, $p=0.017)$. First-year students were more likely to deem government guidance was appropriate (53.1\% first-year students versus $29.1 \%$ final year students, $p=0.004$ ).

Discussion: Although data were only gathered from one institution, this work adds to the growing evidence-based about the impact of COVID-19 on students. Despite additional interventions, student expectations about their university experience still exceeded what was provided during the pandemic.

\section{Reference}

Office for National Statistics (2021). Coronavirus and the impact on students in higher education in England. Available at: https://www.ons.gov.uk/peoplepopulationandcommunity/educatio nandchildcare/articles/coronavirusandtheimpactonstudentsinhigher educationinenglandseptembertodecember2020/2020-12-21

\section{Independent prescribers' preparedness for practice during COVID-19}

Ellen Schafheutle ${ }^{1 *(D)}$, Dianne Bell ${ }^{1}$, Akhil Gupta $^{2}$,

Ali Hindi ${ }^{1}$, Keith Holden ${ }^{2}$, Leonie McCormack ${ }^{1}$

${ }^{1}$ University of Manchester, Division of Pharmacy and Optometry, United Kingdom

${ }^{2}$ University Of Sunderland, School of Pharmacy and Pharmaceutical Sciences, United Kingdom

*Presenting author: ellen.schafheutle@manchester.ac.uk

Keywords: COVID-19, Independent prescribing, Pharmacist practice

Background: Despite exploration of barriers and facilitators to independent prescriber (IP) practice, little is known about how prepared IPs felt during the COVID-19 pandemic (Hindi et al., 2019).

Aim: To investigate if and how the COVID-19 pandemic changed IPs' practice, and whether their IP qualification had been valuable in preparing them for practice during the pandemic.

Method: A questionnaire was developed and piloted to include demographic questions and Likert-style agreement statements. With the ethics committee approval, the questionnaire was distributed electronically (Qualtrics) to 162 IP alumni (2016-2020) from two universities in North England. Data were analysed using SPSS.

Results: Thirty IPs responded (18.5\%), two nurses and 28 pharmacists. Twenty-five respondents were female (83\%); ages ranged from $28-50$ years (mean 35 ). Similar numbers of respondents said their role had stayed the same as a consequence of the COVID-19 pandemic $(12 / 26)$ or become more patient-facing (face-to-face, phone, video: 13/26). When asked about ways in which respondents' roles had changed due to COVID-19, 11/21 said remote consultations had become the default method for their patient interactions. Nineteen respondents $(68 \%)$ described themselves as active prescribers and answered statements about how prepared they felt for advanced clinical roles since the beginning of the COVID-19 pandemic. More than half felt 'somewhat' to 'extremely' prepared for 'prescribing in the absence of direct clinical supervision' $(n=11)$; 'triage/prioritisation of clinical cases' $(n=10)$; 'recognising the deteriorating patient' $(n=10)$; 'conducting remote consultations $(n=10)$; and 'remote 
prescribing' $(n=9)$. Most felt 'not/a little' prepared for 'prescribing in clinical care' $(n=14)$; 'dealing with bereavement' $(n=16)$; 'coping with the dying patient' ( $n=17)$; 'caring for distressed relatives' $(n=18)$.

Discussion: Independent prescribers participating in this study felt their qualification prepared them for various practice changes due to COVID-19. However, some further skills may need to be included to support IPs to better deal with serious illness and death during a pandemic.

\section{Reference}

Hindi, A.M., Seston, E.M., Bell, D., Steinke, D., Willis, S. and Schafheutle, E.I., (2019). Independent prescribing in primary care: a survey of patients', prescribers' and colleagues' perceptions and experiences. Health \& social care in the community, 27 (4), e459e470. https://doi.org/10.1111/hsc.12746

\section{An exploration of the development needs of mentees and mentors using a national mentoring programme}

\author{
Melisa Chakarto ${ }^{1^{*}}$, Kina Vyas², Rhona Auckland ${ }^{2}$, \\ Helen Chang ${ }^{2}$ \\ ${ }^{1}$ University of Nottingham, Nottingham, United Kingdom \\ ${ }^{2}$ Royal Pharmaceutical Society, United Kingdom \\ *Presenting author: paymc3@nottingham.ac.uk
}

Keywords: Development, Mentee, Mentor, Mentoring, Pharmacy

Background: Mentoring is a process where an experienced individual guides a less able individual for their personal or professional development (Ragins and Kram, 2007). Little information exists regarding mentoring in pharmacy; however other studies have found advantageous effects of mentoring programs (Cohen et al., 2007). The Royal Pharmaceutical Society (RPS) implemented a national mentoring programme in 2019 to support the professional development of pharmacists; however, its' value to users has not been fully investigated.

Aim: To explore how mentee and mentor users of a national mentoring platform want to develop further personally and professionally.

Method: A mixed-method approach was utilised. Two online surveys were designed and administered within Qualtrics. Survey one captured views of mentee relationships and their mentoring needs. Survey two focussed on views of mentor relationships and their mentoring development requirements. Data were collected over two weeks in March 2021. Quantitative data were analysed using Statistical Package for the Social Sciences, SPSS version 27, and descriptive statistics performed. Qualitative responses were reviewed and thematically analysed.

Results: A total of 1539 surveys were distributed with 126 returned $(8.2 \%$ response rate), completed by mentor respondents $(n=78)$ and mentee respondents $(n=48)$. Findings suggested $57 \%$ of mentees used the programme for career development, and $11 \%$ cited a desire to improve career-related skills, e.g. transitioning into a new role. Moreover, $62 \%$ of mentors would like to increase their overall mentoring competency, with $25 \%$ selecting guides and handbooks as the best method for this.

Discussion: This study highlights the importance of enhancing both mentor and mentee skills to enable professional development and fulfil desires to progress. Predominantly, mentees highly value career development support from mentors, whilst mentors require appropriate training to equip them with key mentoring skills. Future research could explore outcomes of mentoring relationships for mentees and the impact of training for mentors.

\section{Reference}

Cohen, M.S., Jacobs, J.P., Quintessenza, J.A., Chai, P.J., Lindberg, H.L., Dickey, J., \& Ungerleider, R.M. (2007). Mentorship, learning curves, and balance. Cardiology in the Young, 17 (S4), 164-174. https://doi.org/10.1017/S1047951107001266

Ragins, B.R., \& Kram, K.E. (2007). The handbook of mentoring at work: theory, research, and practice. Los Angeles: Sage Publications

\section{Educational performance management of work- placed learning for foundation pharmacist Trainees Requiring Additional Support (TRAS) within multisector vocational training schemes}

Alice Conway ${ }^{1 *}$, Sarah Purdy ${ }^{1}$, Katie Reygate ${ }^{2}$

${ }^{1}$ East Sussex Healthcare NHS Trust, United Kingdom

${ }^{2}$ Health Education England London and South East Pharmacy, United Kingdom

*Presenting author: Alice.Conway@nhs.net

Keywords: Educational performance management, Progression monitoring

Background: Within Foundation Pharmacist (FP) multisector vocational training schemes (VTS), educational and practice supervisors may uncover concerns outside their educational remit, including patient safety, professionalism or probity problems that are detrimental to FP progression.

Aim: Provide a standardised approach to progression monitoring and escalation, applicable to any multisector VTS 
where there may not be a defined external educational infrastructure linked to the learning programme.

Method: A bespoke TRAS matrix was adapted from existing guidance defining triggers for concerns with respective progressive escalation thresholds based on severity and expected actions at each stage. Significant concerns highlighted for urgent action with referral to wider support guidance, including action plans and health education England reporting processes where applicable. Verbal minuted qualitative evaluation discussions of the matrix by east Sussex multisector foundation to advanced ${ }^{1}$ VTS stakeholders via programme local faculty group, responsible for programme's educational governance prior to wider implementation. Ongoing qualitative evaluation of the matrix as an effective tool is discussed, following each implementation of the tool, to highlight the effectiveness or adaptations required.

Results: The matrix has: 1) Supported differentiation and management of expectations within the scope of the developmental journey versus the job role; 2) Encouraged transparency within the FP supervisor relationship, supporting the identification of TRAS and embracing sensitivities around challenges of performance, progression or specific needs; 3) Encouraged FP reflective practice to identify triggers for seeking further help; 4) Developed capability the following support with perceived weaker performance areas; 5) Been underpinned by National Health Service (NHS) constitutional values and professional standards, and 6) Empowered staff to appropriately escalate urgent problems.

Discussion: The TRAS matrix and supporting guidance is essential process. There is transparency, consistency and empowerment showing that training aligns to the ethos of the NHS constitutional values whilst ensuring the wellbeing of both patients and FPs. This matrix could be incorporated into other multisector VTS educational training programmes.

\section{Reference}

East Sussex Multisector Foundation to Advanced (MFtA) Vocational Training Scheme (2020). Available at:

https://www.lasepharmacy.hee.nhs.uk/dyn/_assets/_folder4/found ation-pharmacists-pages/vts/esbtvtsheewebsiteinformation.pdf

\section{Early-career pharmacists' and their supervisors' experiences of foundation training in general practice}

\author{
Ali Hindi* (D), Sarah Willis $(D)$ Ellen Schafheutle $(D)$
}

Centre for Pharmacy Workforce Studies, The University of Manchester, Manchester, United Kingdom

*Presenting author: ali.hindi@manchester.ac.uk
Keywords: Clinical supervision, Experiential learning, Foundation training, General practice, Pharmacists, Placements, Primary care

Background: There is no all-England cross-sector training programme for newly-qualified pharmacists. Health education England commissioned the South-East London Foundation Pharmacist Vocational Training Scheme (SEL-FPVTS) to feasibility-test possible models of multisector postregistration foundation training (Health Education England 2021).

Aim: To evaluate the implementation of general practice foundation placements for newly-qualified pharmacists on the SEL-FP-VTS, including enablers and barriers to a successful learning experience.

Method: Semi-structured telephone interviews with all eight SEL-FP-VTS foundation pharmacists and their 13 general practice (GP) based pharmacist and general practitioner (GP) supervisors covered placement expectations, trainees' learning/ practice experiences, knowledge and skills gained, and competence/ confidence to apply these in the general practice setting. Data were analysed thematically.

Results: The main benefits of GP placements were seen as providing a good understanding of the general practice and its place in the patient journey. Pharmacists particularly enhanced their holistic, patient-centred clinical decisionmaking and consultation skills. Supervision played a critical role in supporting the gradual development of competence. Supervision was more direct initially, moving to more at armslength (with pre-briefing and de-briefing) to encourage foundation pharmacists to work increasingly independently in patient-facing activities. GP supervisors provided formal teaching/educational based support, while GP-based pharmacist supervisors provided day-to-day feedback and supervision. Interprofessional learning within the multidisciplinary team was viewed as essential. Foundation pharmacists and supervisors agreed that six months was the minimum duration for a GP placement, to allow foundation pharmacists to settle, learn, and contribute to clinical services. Concerns around continuation of service provision on placement completion were raised, despite foundation pharmacists being supernumerary. Moving forward, supervisors wanted more clarity around competency levels expected of foundation pharmacists.

Discussion: This evaluation generated a multifaceted understanding of factors impacting early career pharmacists' practice and learning in GP. This makes an important contribution to how best to support a pharmacist workforce able to practise clinically across settings.

\section{Reference}

Health Education England (2021), South East London Foundation Pharmacist Vocational Training Scheme (SEL FP VTS), Available at: https://www.lasepharmacy.hee.nhs.uk/early-careers/hee-pilotprogrammes/ 


\title{
Pharmacy Education Virtual Conference Proceedings 2021: The digital switch
}

\author{
Manchester, United Kingdom
}

Poster Presentation

\author{
Surviving the pitfall of learning biology and \\ physiology: 'Start strong' and 'Stay strong' \\ S. Amadesi*, J. Gunner, B. Stoyanova \\ University of Reading, School of Pharmacy, Reading, United \\ Kingdom \\ *Presenting author: s.amadesi@reading.ac.uk
}

Keywords: Biology, Difficulties, Learning needs, Learning tool, Pharmacy, Physiology, Support

Background: Biology and physiology topics are the foundations of the Master of Pharmacy (M.Pharm.) degree. It was noticed that $\sim 20 \%$ of year one M.Pharm. students failed biology and physiology-focused module. Understanding what the challenges encountered by year one students when learning are and what type of support they may need to improve their achievements is essential to ensure academic success (Brooker, Brooker and Lawrence, 2017).

Aim: To conduct focus group discussions with M. Pharm. students and gain an in-depth understanding of students' difficulties and learning needs, as well as views and preferences in relation to learning tools required when learning biology and physiology topics.

Method: Two multiple-category design focus group discussions were organised with three year-one, three yeartwo, and one year-three M. Pharm. students. A 'topic guide', with prompting questions, was used to structure the discussions that were recorded, transcribed, synthesised and then analysed by thematical analysis (Office of Institutional Research, Effectiveness, and Planning, 2005).

Results: After coding the participants' responses, the following major themes were identified: 'Year-one challenges', 'Delivery of content', and 'Tools'. In particular, the 'lack of pre-knowledge' on some of the topics, difficulties in 'appreciating the learning objectives' and adapting to the 'pace of delivery' of the lectures where among the major struggles experienced by students. On the other hand, the use of lecture's screencasts, videos, tutorials and formative online assessments were highlighted as beneficial learning tools.

Discussion: Adapting to different teaching approaches and managing workload seemed to be the major challenges encountered by students. Managing students' expectations at the start of the university journey may be important to support academic transition and improve students' engagement and thus their overall experience. The use of technology and interactive sessions and the introduction of formative assessments should be considered to support students' learning and thus improve their academic achievements.

\section{Reference}

Brooker A., Brooker S., \& Lawrence J (2017). First year students' perceptions of their difficulties. Student Success, 8(1), 49-62. https://studentsuccessjournal.org/article/view/492

Trinity College of Arts \& Sciences at Duke University (2005). Guidelines for Conducting a Focus Group. Durham, NC: Eliot \& Associates. Available at:

https://universityplanning.wp.olemiss.edu/wpcontent/uploads/sites/98/2016/05/Trinity_Duke_How_to_Conduct _a_Focus_Group.pdf 


\section{Counselling triplets: Introducing peer learning into professional practice classes

\author{
Helen Boardman* iD, Vibhu Solanki \\ University of Nottingham, United Kingdom
} \\ *Presenting author: Helen.boardman@nottingham.ac.uk}

Keywords: Counselling skills, Peer learning

Background: Peer learning is well recognised to promote skills such as team working, reflection and identification of learning needs (Boud, Cohen and Sampson, 1999). For the professional practice classes, student triplet counselling skills practice was introduced where groups of three students learn from others' performance and a facilitated feedback discussion.

Aim: To evaluate student views of triplet counselling.

Method: Students completed a questionnaire about their views of counselling triplets after their first experience. Questionnaire responses were entered into SPSS for analysis which consisted of frequency counts with percentages and open questions that were analysed thematically.

Results: Sixty year-one and 81 year-two students completed the questionnaire (39\% response), $70 \%(n=98)$ were female. Almost all students $(99 \%, n=193)$ agreed that developing their communication skills was essential to their future practice. Despite one-third of students $(36 \%, n=50)$ reported concern about demonstrating their communication skills in front of peers, most $(77 \% \mathrm{n}=108)$ reported being comfortable discussing their skills with peers. Sharing feedback with peers was reported to benefit their learning by $91 \%(n=128)$ of students with a similar number $(86 \%, n=124)$ reporting that working in this way improved their communication skills. New ideas about communication skills and building confidence were identified as the key benefits in the open questions, although some did report that they felt pressure to do well in their consultations and were concerned about how the others might react to the feedback they gave.

Discussion: Students reported clear benefits to their learning in working with peers, despite some concerns about practising in front of other students. Whilst the comparatively low response rate means it is unknown whether this reflects the views of the wider student body, the positive response to the initiative meant this initiative was retained for students across all years of professional practice teaching.

\section{Reference}

Boud, D., Cohen, R., \& Sampson, J. (1999) Peer learning and assessment. Assessment \& Evaluation in Higher Education, 24 (4), 413-426. https://doi.org/10.1080/0260293990240405

\section{'Narrowing the gap': Supplementary chemistry tutorials for non A-level students of pharmacy}

Heather Coleman iD

School of Pharmacy and Pharmaceutical Sciences, Ulster University, Coleraine, BT52 1SA, Northern Ireland

*Presenting author: h.coleman@ulster.ac.uk

Keywords: First-year M.Pharm., Supplementary chemistry tutorial, Widening access

Background: As student cohorts become larger and more diverse, there is a need to comprehend how to engage and support all students. Ulster University is a "civic university", encouraging "a diverse university community" (Ulster University 2021). M.Pharm. students entering on the nontraditional route of A-levels, i.e. Leaving certificate, Access courses, Business and Technology Education Council (BTEC) or an international qualification, can struggle with the chemistry content in the first term of the first year. This has been reflected in the exam results and through feedback from students.

Aim: To implement supplementary chemistry tutorials for students struggling with the chemistry component of a firstterm first-year module.

Method: Subject areas within the A-level syllabus were identified and aligned with the first year, first term module chemistry components. A questionnaire was devised to determine what the needs were and distributed to all firstyear students at the start of the term. The tutorials covered an A-level chemistry fact file each week. A Ph.D. student with a strong background in chemistry took the tutorials.

The academic staff member met with the Ph.D student twice a week to discuss material to be covered and any feedback from students. The academic also worked closely with students to understand the problem areas through informal discussions, minute papers at the end of each of the tutorials and teaching assessment questionnaires at the end of term. The number of students attending varied each week from five to fifteen (from a class of 35 students).

Results: Based on the feedback from students, the Ph.D. tutor and the exam results, the extra chemistry tutorials were deemed a success. The fail rate for the module exam decreased significantly from $21.3 \%$ to $6.1 \%$ in the academic year after implementation.

Discussion: Due to the success of the tutorials, they have become part of the practice within the first-year cohort. This practice is transferrable as chemistry in another school or as a different subject area such as mathematics which is frequently seen as a challenge in teaching first-year students across numerous disciplines (Anderton et al., 2017). 


\section{Reference}

Anderton, R., Hine, G., \&Joyce, C. (2017). Secondary school mathematics and science matters: Academic performance for secondary students transitioning into university allied health and sciences courses. International Journal of Innovation in Science and Mathematics Education, 25 (1), 34-37.

https://openjournals.library.sydney.edu.au/index.php/CAL/article/vi ew/11317

Ulster University (2021). Five-year strategic plan. Fiftieth-year strategic vision: five and fifty. Available at: https://www.ulster.ac.uk/fiveandfifty/home

\section{Action required: An analysis of $M$. Pharm. student protected characteristics data reveals females outperform males}

Lezley-Anne Hanna* (D), Sharon Haughey, Paul McCague, Maurice Hall L-A. Hanna D, S. Haughey, P. McCague, M. Hall

Queen's University Belfast, United Kingdom

*Presenting author: I.hanna@qub.ac.uk

Keywords: Academic performance, Pharmacy students, Progression, Protected characteristics

Background: In recent years, many organisations, including the General Pharmaceutical Council, have placed great importance on equality, diversity, and inclusion (General Pharmaceutical Council, 2021). This is timely given differences in attainment for their registration assessment (Robinson, 2018).

Aim: To determine, from protected characteristics data (i.e., disability, age, sex, race), whether differences existed in Queen's University Belfast M.Pharm. student progression and academic performance.

Method: Available de-identified data were requested and obtained from the central university in November 2020 in relation to M.Pharm. student degree classification and progression. Data analysis mainly took the form of descriptive statistics such as frequencies and percentages.

Results: Data from the last three academic years were included in the analysis (i.e. 2017/18, 2018/19 and 2019/20). Student numbers were small for disability (one in 2017/18 graduates, three in 2018/19 graduates and six in 2019/20 graduates), age outside the $18-20$ years old range, and race other than White or Asian. In all cohorts, a higher proportion of males were required to repeat modules than females, and a higher proportion of females obtained first-class honours degree classifications $(54.3 \%$ females vs $29.6 \%$ males in
$2017 / 18,59.5 \%$ females vs $30.4 \%$ males in $18 / 19$, and $66.2 \%$ females vs $37.1 \%$ males in $19 / 20$ ).

Discussion: While small numbers and limited data made it difficult to reach meaningful conclusions, differences appear to exist for sex. An action plan has since been developed to address these differences and includes increasing the number of male role models and support staff, having an emphasis on male mental health, including male student reflections in teaching material for future cohorts, and ensuring there is a broad range of appropriate teaching and assessment approaches in the degree programme. Lastly, we hope this work provides an impetus for others to follow this approach in their own context.

\section{Reference}

General Pharmaceutical Council (2021). Annual report 2020-21. London: GPhC. p26-29. Available at: https://www.pharmacyregulation.org/sites/default/files/document/ gphc-annual-report-2020-21.pdf

Robinson, J. (2018). Black African pharmacy students still least likely to pass GPhC prereg exam. Pharmaceutical Journal, 301(7917). https://doi.org/10.1211/PJ.2018.20205438

\section{Who am I? Opinions of year-two students on professional identity}

Mary-Carmel Kearney ${ }^{1 *}$, Joanne Brown ${ }^{2}$, Fiona Hughes ${ }^{1}$

${ }^{1}$ School of Pharmacy, Queen's University, Belfast, United Kingdom

${ }^{2}$ Northern Health and Social Care Trust., United Kingdom

*Presenting author: Mary-carmel.kearney@qub.ac.uk

Keywords: Patient-centred workshop, Professional identity, Professionalism, Transition

Background: Professional identity (PI) formation is of increasing interest amongst healthcare professional educators. There is no agreed definition of $\mathrm{PI}$, but it is considered to be a multifaceted interaction between an individual's perception of themselves and their career (Vivekananda-Schmidt, Crossley and Murdoch-Eaton, 2015). It has been reported that students with a strong sense of PI can transition more readily into the workplace and tend to have greater self-confidence in fulfilling the requirements of their role, particularly more complex and uncertain aspects of practice (Noble et al., 2014). In pharmacy education, the concept of $\mathrm{PI}$ is more pertinent than ever as the profession evolves at a pace without clear evidence of how to develop PI.

Aim: To explore opinions of year two students on $\mathrm{PI}$, the aspects of the M.Pharm. degree programme that make them 
feel most like a pharmacist and to evaluate the impact of a novel patient-centred workshop on PI development.

Method: Year two M. Pharm. students at Queen's University Belfast (QUB) attended a novel patient-centred workshop. Pre-and post-workshop questionnaires were administered to explore students' understanding of PI. Questionnaire content was informed by a review of relevant literature (e.g. Crossley and Vivekananda-Schmidt, 2009) and the M.Pharm. at QUB to construct appropriate questions that would meet the aims of the study. Data were analysed primarily by descriptive statistics. Responses from opened-ended questions were thematically analysed.

Results: Response rates to the pre-workshop and postworkshop questionnaires were $94.79 \%$ (91/96) and $92.71 \%$ (89/96), respectively. Presented in Table I are five themes that emerged from responses to the question 'What does professional identity mean in your opinion?' Students indicated that classes centred on patients made them 'feel more like a pharmacist' whereas those based in a laboratory did not. Over $95 \%$ of students agreed that the workshop had a positive impact on their PI development.

Table I: Theme and sampler quotations on students response to 'What does professional identity means to you?' $(n=69)$

\begin{tabular}{cll}
\hline $\begin{array}{c}\text { Theme } \\
\text { number }\end{array}$ & Theme title & Exemplar quotation \\
\hline $\mathbf{1}$ & $\begin{array}{l}\text { Attitude, } \\
\text { behaviour } \\
\text { and values }\end{array}$ & $\begin{array}{l}\text { "It means having a broad and good } \\
\text { knowledge about your career, having } \\
\text { good attitude and behaviour while } \\
\text { consulting customers/patients and } \\
\text { being responsible for what you're } \\
\text { doing." [S1] }\end{array}$ \\
\hline $\mathbf{2}$ & $\begin{array}{l}\text { Knowledge, } \\
\text { skills and } \\
\text { experience }\end{array}$ & $\begin{array}{l}\text { "The ability of having good knowledge } \\
\text { in the field you're working in and being } \\
\text { able to communicate it well" [S65] }\end{array}$ \\
\hline $\mathbf{3}$ & $\begin{array}{l}\text { Interaction } \\
\text { with and } \\
\text { perception of } \\
\text { others }\end{array}$ & $\begin{array}{l}\text { "The role you provide to the patient as } \\
\text { you work as part of a multidisciplinary } \\
\text { team." [S35] }\end{array}$ \\
\hline $\mathbf{4}$ & $\begin{array}{l}\text { Person and } \\
\text { role }\end{array}$ & $\begin{array}{l}\text { "With respect to pharmacy - the idea } \\
\text { that pharmacy is an important part of } \\
\text { life/more than just career" [S34] }\end{array}$ \\
\hline & Unsure & "Not too sure" [S12] \\
\hline
\end{tabular}

Discussion: Year two M.Pharm. students at QUB have varying perceptions of what PI means. The majority of students report that they have started to develop a sense of $\mathrm{PI}$ and this is particularly facilitated by patient and profession specific learning opportunities.

\section{Reference}

Crossley, J., \& Vivekananda-Schmidt, P. (2009). The development and evaluation of a professional self identity questionnaire to measure evolving professional self-identity in health and social care students. Medical Teacher, 31, e603-7. https://doi.org/10.3109/01421590903193547
Noble, C., O’Brien, M., Coombes, I., Shaw, P.N., Nissen, L., \& Clavarino, A. (2014). Becoming a pharmacist: Students' perceptions of their curricular experience and professional identity formation. Currents in Pharmacy Teaching and Learning, 6, 327-39. https://doi.org/1016/j.cptl.2014.02.010

Vivekananda-Schmidt, P., Crossley, J., \& Murdoch-Eaton, D. (2015). A model of professional self-identity formation in student doctors and dentists: a mixed method study. BMC Medical Education, 15 83. https://doi.org/10.1186/s12909-015-0365-7

\section{A comparison of student perceptions of peer teaching by NICE Champions when delivered online versus face-to-face}

T. Kurani ${ }^{1}$, M-C. Kearney ${ }^{1}$, S. Greene ${ }^{1}$, A. Weist ${ }^{2}$, L. Edgar ${ }^{2}$, J. Jefferies ${ }^{2}$, Y. Hsia ${ }^{1}$, B. Girvin ${ }^{1 *}$

${ }^{1}$ School of Pharmacy, Queen's University Belfast, Northern Ireland

${ }^{2}$ National Institute for Health and Care Excellence

*Presenting author: b.girvin@qub.ac.uk

Keywords: Face-to-Face learning, NICE student champion, Online learning, Peer teaching

Background: The school of pharmacy at Queen's University Belfast has been partnered with the National Institute for Health and Care Excellence (NICE) student champion scheme since 2011 (NICE, 2021). In 2019 and 2020 Champions from year-three received training from NICE on how to use evidence search and cascaded this training to other students in their year group. The cascade training was face-to-face in 2019 and online in 2020 due to the pandemic.

Aim: To compare student perceptions of being taught by their peers online versus face-to-face.

Method: Following ethical approval, a paper questionnaire was distributed to year-three M. Pharm. students (2020 cohort, $n=94$ ) assessing their opinions of being trained via Microsoft Teams on the NICE evidence search by their peers. It comprised mainly closed questions incorporating a fivepoint Likert scale to measure level of agreement to statements regarding the training. Answers were compared to those provided in a similar questionnaire distributed the previous year (2019 cohort, $n=88$ ), who were trained face-toface. Descriptive analyses were performed using SPSS software. The Mann Whitney $U$ test was performed to detect significant differences $(p \leq 0.05)$ between the two cohorts.

Results: Questionnaire response rates were 97\% (2020 cohort) and 77\% (2019 cohort). Statistically significant differences were found between cohorts for agreement with statements such as finding the workshop enjoyable and 
being a beneficial use of time (Table I), with students being in favour of the face-to-face teaching. However, the 2020 cohort were more strongly in agreement with statements suggesting the training should occur earlier in the curriculum.

Table I: Statements where statistically significant differences occurred in mean Likert scores between the 2020 (online teaching) versus the 2019 (face-to-face teaching) cohorts

\begin{tabular}{|c|c|c|c|}
\hline Statement & $\begin{array}{l}\text { Mean } \\
\text { Likert } \\
\text { score } \\
2019 \\
( \pm S D)^{*}\end{array}$ & $\begin{array}{l}\text { Mean } \\
\text { Likert } \\
\text { score } \\
2020 \\
( \pm S D)^{*}\end{array}$ & $\begin{array}{c}p \\
\text { value }\end{array}$ \\
\hline $\begin{array}{l}\text { I found the workshop } \\
\text { enjoyable }\end{array}$ & $\begin{array}{c}4.03 \pm 0.73 \\
(n=68)\end{array}$ & $\begin{array}{c}3.65 \pm 0.88 \\
(n=91)\end{array}$ & 0.01 \\
\hline $\begin{array}{l}\text { I think that it was necessary } \\
\text { for the workshop to be } \\
\text { compulsory }\end{array}$ & $\begin{array}{c}3.96 \pm 0.93 \\
(n=68)\end{array}$ & $\begin{array}{c}3.45 \pm 1.13 \\
(n=91)\end{array}$ & 0.008 \\
\hline $\begin{array}{l}\text { I would have attended the } \\
\text { workshop even if it had } \\
\text { been optional }\end{array}$ & $\begin{array}{c}3.68 \pm 1.19 \\
(n=67)\end{array}$ & $\begin{array}{c}3.16 \pm 1.13 \\
(n=91)\end{array}$ & 0.002 \\
\hline $\begin{array}{l}\text { The workshops were } \\
\text { timetabled for an } \\
\text { appropriate length of time }\end{array}$ & $\begin{array}{c}4.37 \pm 0.62 \\
(n=68)\end{array}$ & $\begin{array}{c}4.02 \pm 0.93 \\
(n=91)\end{array}$ & 0.041 \\
\hline $\begin{array}{l}\text { The workshop was a } \\
\text { beneficial use of my time }\end{array}$ & $\begin{array}{c}4.26 \pm 0.58 \\
(n=68)\end{array}$ & $\begin{array}{c}3.67 \pm 1.01 \\
(n=91)\end{array}$ & $<0.001$ \\
\hline $\begin{array}{l}\text { Level three is the most } \\
\text { beneficial year to receive } \\
\text { this training }\end{array}$ & $\begin{array}{c}4.04 \pm 0.93 \\
(n=68)\end{array}$ & $\begin{array}{c}3.30 \pm 1.17 \\
(n=91)\end{array}$ & $<0.001$ \\
\hline $\begin{array}{l}\text { Having knowledge of NICE } \\
\text { evidence search tool in } \\
\text { Level one and Level two } \\
\text { would have been useful }\end{array}$ & $\begin{array}{c}3.43 \pm 1.05 \\
(n=68)\end{array}$ & $\begin{array}{c}3.75 \pm 1.08 \\
(n=91)\end{array}$ & 0.047 \\
\hline $\begin{array}{l}\text { I will use the NICE evidence } \\
\text { search tool when I am } \\
\text { qualified as a pharmacist }\end{array}$ & $\begin{array}{c}4.44 \pm 0.76 \\
(n=68)\end{array}$ & $\begin{array}{c}4.08 \pm 1.04 \\
(n=90)\end{array}$ & 0.048 \\
\hline $\begin{array}{l}\text { The peer teachers were } \\
\text { easy to understand }\end{array}$ & $\begin{array}{c}4.46 \pm 0.74 \\
(n=68)\end{array}$ & $\begin{array}{c}4.18 \pm 0.85 \\
(n=91)\end{array}$ & 0.032 \\
\hline $\begin{array}{l}\text { The peer teachers made the } \\
\text { workshop an interesting } \\
\text { and enjoyable experience }\end{array}$ & $\begin{array}{c}4.25 \pm 0.85 \\
(n=68)\end{array}$ & $\begin{array}{c}4.01 \pm 0.82 \\
(n=91)\end{array}$ & 0.049 \\
\hline $\begin{array}{l}\text { I feel it would be useful to } \\
\text { incorporate more peer } \\
\text { teaching into the pharmacy } \\
\text { degree programme }\end{array}$ & $\begin{array}{c}3.85 \pm 0.86 \\
\quad(n=68)\end{array}$ & $\begin{array}{c}3.27 \pm 1.18 \\
(n=91)\end{array}$ & 0.003 \\
\hline
\end{tabular}

Discussion: This study supports the incorporation of more peer teaching into the M. Pharm. degree. This is in keeping with recommendations that students 'support the learning and development of others' (GPhC, 2021). Students prefer peer teaching to be face-to-face. Should online training be mandatory, there is potential to explore how it could be made more interesting and enjoyable for students.

\section{Reference}

General Pharmaceutical Council (2021). Standards for the initial education and training of pharmacists. London, GPhC. Available at: https://www.pharmacyregulation.org/sites/default/files/document/ standards-for-the-initial-education-and-training-of-pharmacistsjanuary-2021_0.pdf

NICE (2021). NICE Student Champions. Available at: https://www.nice.org.uk/get-involved/student-champions

\section{Factors influencing Chinese students' and parents' preferences for studying articulated pharmacy programmes in the United Kingdom

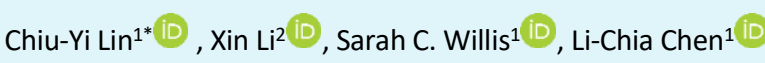 \\ ${ }^{1}$ School of Health Sciences, University of Manchester, Manchester, United Kingdom \\ ${ }^{2}$ School of Pharmacy, Nanjing Medical University, Nanjing, China \\ *Presenting author: chiu-yi.lin@manchester.ac.uk}

Keywords: Articulated pharmacy curriculum, Chinese students, International programmes, Undergraduate pharmacy education

Background: In the past two decades, international articulated pharmacy programmes have increasingly been offered by higher education institutions in China (CoverdaleJones, 2013). Articulated programmes involve a formal agreement between two institutions; students beginning their degree programme at one university before transferring to a similar programme at another university (Zhong, 2020). However, little is known about students' and their parents' views about articulated international programmes.

Aim: To explore Chinese high school students' and their parents' preferences regarding different models of articulated curriculum design and the factors influencing their preferences.

Method: A survey was conducted in Jiangsu province in China in July-September 2020 using self-reported questionnaires capturing preferences for different articulated programme models and factors influencing this. A purposive sample of high school students $(n=2069)$ who took or will take the National College Entrance Examination in 2020 or 2021 and their parents $(n=1576)$ were recruited at university fairs or by researchers' networks. The association between participants' preference for different programme and associated personal and institutional factors (Klahr, 2000) was analysed using descriptive and logistic regression.

Results: Overall, 1,751 students and 1,339 parents completed a survey. Univariate analysis showed all factors were associated with preferences for articulated programmes. The 
multivariate analysis found some factors that dominated decision-making on choices for the various durations of overseas study. Students' decisions were mainly driven by academic performance, benefit to future careers, and additional degrees. However, parents' choice was driven by student intentions, improved language skills, and an additional degree (Table I).

Table I: Factors significantly associated with participants' choices on various international articulation programmes

\begin{tabular}{|c|c|c|c|c|c|c|}
\hline \multirow{2}{*}{$\begin{array}{l}\text { Participants } \\
\text { Type of articulation programmes }\end{array}$} & \multicolumn{3}{|c|}{ High school students } & \multicolumn{3}{|c|}{ Parents of high-school students } \\
\hline & $2+2$ year & $3+1$ year & $4+1$ year & $2+2$ year & $3+1$ year & $4+1$ year \\
\hline Academic performance & $\begin{array}{c}2.01 \\
(1.40,2.87)\end{array}$ & $\begin{array}{c}1.75 \\
(1.21,2.53)\end{array}$ & $\begin{array}{c}1.84 \\
(1.30,2.61)\end{array}$ & - & $\begin{array}{c}1.68 \\
(1.15,2.46)\end{array}$ & $\begin{array}{c}1.73 \\
(1.19,2.52)\end{array}$ \\
\hline $\begin{array}{l}\text { Parents' supportive attitude } \\
\text { Student intention }\end{array}$ & - & $\begin{array}{c}2.26 \\
(1.56,3.26)\end{array}$ & - & $\begin{array}{c}1.75 \\
(1.26,2.44)\end{array}$ & $\begin{array}{c}1.72 \\
(1.22,2.41)\end{array}$ & $\begin{array}{c}2.34 \\
(1.67,3.28)\end{array}$ \\
\hline The cost & - & - & - & $\begin{array}{c}0.66 \\
(0.46,0.94)\end{array}$ & - & $\begin{array}{c}0.59 \\
(0.41,0.85)\end{array}$ \\
\hline $\begin{array}{l}\text { The benefits of study abroad experience to } \\
\text { your future career }\end{array}$ & $\begin{array}{c}1.68 \\
(1.17,2.41)\end{array}$ & $\begin{array}{c}1.65 \\
(1.13,2.40)\end{array}$ & $\begin{array}{c}1.77 \\
(1.24,2.52)\end{array}$ & - & - & - \\
\hline Improvement in language skills & - & - & - & $\begin{array}{c}1.58 \\
(1.04,2.40)\end{array}$ & $\begin{array}{c}1.63 \\
(1.06,2.50)\end{array}$ & \\
\hline An additional degree & $\begin{array}{c}2.21 \\
(1.56,3.11)\end{array}$ & $\begin{array}{c}1.95 \\
(1.37,2.79)\end{array}$ & $\begin{array}{c}1.91 \\
(1.37,2.67)\end{array}$ & $\begin{array}{c}2.49 \\
(1.68,3.71)\end{array}$ & & $\begin{array}{c}2.35 \\
(1.59,3.48)\end{array}$ \\
\hline Cultural differences & - & - & $\begin{array}{c}0.71 \\
(0.55,0.92)\end{array}$ & - & - & - \\
\hline
\end{tabular}

Note: The articulation programmes vary in the duration studying in two institutes. This table presents the statistically significant results $(p<0.05)$ of the multivariate logistic regression analysis in odds ratios (OR) with $95 \%$ confidence intervals $(95 \% \mathrm{Cl})$. Other factors with no significant difference, i.e. independent living skills, family's financial situation, university's reputation, subject ranking, teaching quality and facilities, official language of the destination country, location of the destination country, and security of the destination country are not presented in this table.

Discussion: This is the first study to investigate Chinese students' and their parents' perceptions on choosing articulated programmes. The results provide insights to inform further development of pharmacy articulated programmes for Chinese students. A dual degree award is regarded as an added value. Further career development is also an attractive point for students.

\section{Reference}

Coverdale-Jones, T. (2013) Transnational Higher Education in the Asian Context. London: Palgrave Macmillan

Klahr, SC., \& Ratti, U (2000). Increasing Enginering Student Participation in Study Abroad: A Study of U.S. and European Programs. Journal of Studies in International Education, 4(1), 79102. https://doi.org/10.1177/102831530000400106

Zhong, R., Chen, Y., Wang, D., Xiao, F. (2020). Study on cross-cultural adaptability of students of articulation program - taking chinese students studying abroad at Harding University in the US as an example. Open Journal of Social Sciences, 8, 56-70. https://doi.org/ $10.4236 /$ jss.2020.812006

\section{Spoken propositional idea density, a measure to help second language English speaking students and level the field: A multicentre cohort study}

Andrew M. Lunn ${ }^{*}$ (D) , Daniel Matthias Bürkle², Rebecca Ward ${ }^{1}$, Alice P. McCloskey ${ }^{3}$, Adam Rathbone ${ }^{4}$ (D) Aaron Courtenay ${ }^{5}$, Rachel Mullen ${ }^{3}$, Andrea Manfrin ${ }^{1}$ (iD

${ }^{1}$ School of Pharmacy and Biomedical Sciences, The University of Central Lancashire, Preston, PR1 2HE, United Kingdom

${ }^{2}$ School of Humanities, Language and Global Studies, The University of Central Lancashire, Preston, PR1 2HE, United Kingdom

${ }^{3}$ School of Pharmacy and Biomolecular Sciences, Liverpool John Moores University, Liverpool L3 2AJ, United Kingdom

${ }^{4}$ School of Pharmacy, Newcastle University, Newcastle, NE1 TRU, United Kingdom

${ }^{5}$ School of Pharmacy and Pharmaceutical Sciences, Ulster University, Cromore Road, Coleraine, BT52 1SJ, United Kingdom

*Presenting author: Alunn@uclan.ac.uk

Keywords: Attainment differential; Equality, diversity and inclusion (EDI); Idea/concept density; International students; Psycholinguistics

Background: Idea density is defined as the number of propositions used divided by the total words in either spoken 
or written text. It has been shown to influence comprehension time, potentially differently in first and second language speakers (Bloomfield et al., 2010).

Aim: This study aimed to determine the effect of spoken idea density on undergraduate student comprehension in first and second language English speakers.

Method: Students watched two online lectures, subsequently answering ten multiple choice questions on them. Students received two lectures and were randomly assigned to have one of these more idea dense (MID) and one less idea dense (LID). Other than ID, equivalent lectures used the same slides, lasted similar times and were presented at similar syllables per minute.

Results: Seventy-five undergraduate students across four United Kingdom (UK) pharmacy departments completed the study, achieving a higher median score after an LID lecture $(L I D=7(3), M I D=6(3), P=0.04)$. Of these, 63 were first language and 12 second language speakers. Artificial neural network models revealed language as the main predictor of exam performance. The odds ratio (OR) of obtaining $\geq 70 \%$ after MID lectures was six-time higher for the first language versus second language English speakers (OR=5.963, 95\% Cl 1.080$32.911, p=0.041)$. The $\mathrm{OR}$ was not significant when receiving LID lectures (OR=2.298, 95\% $\mathrm{Cl} 0.635-8.315, p=0.205)$. Second language speakers benefited from receiving LID instead of MID lectures, achieving a $10.8 \%$ score increase versus a $3.2 \%$ increase obtained by first language speakers.

Discussion: Whilst the results are significant, the sample size is small and not equally distributed between first and second language speakers. However, the propositional idea density of lectures has been shown to directly influence students' comprehension, and disproportionately for second language speakers; revealing the possibility of reduced spoken idea density in levelling the attainment differential between first and second language speakers on pharmacy courses in the UK.

\section{Reference}

Bloomfield, A., Wayland, S.C., Rhoades, E., Blodgett, A., Linck, J. \& Ross, S. (2010). What makes listening difficult? Factors affecting second language listening comprehension. (Technical Report TTO 81434 E.3.1). College Park, MD: University of Maryland Center for Advanced Study of Language. Available at: https://apps.dtic.mil/sti/pdfs/ADA550176.pdf

\section{A questionnaire-based study to investigate future pharmacists' views on over-the-counter medicines, including their place within evolving pharmacy practice}

\author{
Alana Murphy*, Lezley-Anne Hanna iD, Maurice Hall \\ Queen's University Belfast, United Kingdom \\ *Presenting author: amurphy77@qub.ac.uk
}

Keywords: Over-the-counter medicine, Pharmacy student, Questionnaire

Background: Facilitating self-care is an important role for pharmacists worldwide, as evidenced by the International Pharmaceutical Federation's digital programme (International Pharmaceutical Federation, 2021). Moreover, wider access to medicines can be achieved through the deregulation of prescription-only medicine (POM) to overthe-counter (OTC) medicine status.

Aim: To ascertain final year pharmacy students' views on OTC medicines and consultations.

Method: Following ethical approval and an email invitation to participate, data about OTC medicines and consultations were collected from consenting students at Queen's University Belfast via a pre-piloted paper-based questionnaire (November 2020). Data were coded and analysis mainly took the form of descriptive statistics. Nonparametric tests (including Mann-Whitney $U$ Test) were employed to determine whether there were differences in responses by gender with significance set at $p<0.05$ a priori.

Results: A response rate of $87.6 \%$ (78/89) was obtained; $34.6 \%(27 / 78)$ respondents were male and $65.4 \%(51 / 78)$ were female. While all respondents appreciated the value of an evidence-based approach to optimise patient care, $75.6 \%$ (59/78) considered the placebo effect played an important role with OTC medicines. Females were more likely to feel confident recommending OTC emergency hormonal contraception than males $(p=0.002$ for levonorgestrel and $p$ $=0.011$ for ulipristal acetate). The majority of respondents [(96.2\% (75/78)] were in agreement that OTC consultations should remain a fundamental role for pharmacists and $69.2 \%$ (54/78) deemed OTC consultations have the potential to be as complex as independent prescribing. Similarly, $62.8 \%$ (49/78) thought OTC consultations were potentially as complex as vaccine administration. However, $61.5 \%$ (48/78) considered that more medicines should not be deregulated from prescription-only status.

Discussion: Although data were only gathered from one institution, it is apparent that OTC consultations are still viewed as an key part of practice for these future pharmacists. Having confidence recommending a range of 
medicines and incorporating evidence into patient interactions needs to be reinforced, in preparation for expanding counter-prescribing and independent prescribing roles.

\section{Reference}

International Pharmaceutical Federation (2021). FIP Development goals digital programme 2021. Available at:

https://events.fip.org/programme/fip-development-goals-digitalprogramme-2021/

\section{High stakes online OSCEs in a pandemic}

Natalie Lewis*, Mark Brennan, Gagan Degun, Emma Price, Sima Hassan

Aston University, Birmingham, United Kingdom

*Presenting author: Lewisn1@aston.ac.uk

Keywords: Assessment, Online, Objective Structured Clinical Examination, Pandemic

Background: Objective Structured Clinical Examinations (OSCEs) are utilised at Aston University to ensure students possess the core competencies to enter into foundation pharmacy training. Traditionally face-to-face assessments, an alternative online format was required due to the impact of COVID-19.

Aim: The aim was to run an eight station OSCE online for final year M.Pharm. and Overseas Pharmacy Assessment Programme (OSPAP) students.

Method: A team led the design stages blueprinting, approving and standard setting of eight (10 minute) OSCE stations; three oral synchronous interactive using blackboard collaborate, and one asynchronous interactive and four asynchronous independent tasks delivered via the virtual learning environment. Learning from a previous study (Kakadia et al., 2020) staff were given preparation in a practice environment, multiple streams were used to reduce student traffic in the live assessment, clear lines of staff communication were signposted and additional staff were on standby. Students were orientated with practice stations employing the same format and given required resources in advance. Multiple matched versions of stations were written to ensure assessment integrity.

Results: M. Pharm. students had three opportunities in the cycle to complete the assessment; the results can be seen in Table I. Only two students had technical issues that resulted in their attempt being deferred to week 26. Other technical issues did not affect the assessment outcome for the students. Overall, $158 \mathrm{M}$. Pharm. and 19 overseas pharmacists' assessment programme (OSPAP) students completed the OSCEs by week 28 with pass rates of $99.4 \%$ and $100 \%$ respectively. No complaints were received and all sittings ran to time. Initial positive comments from staff and students highlighted; clarity of instruction, preparation provided and general organisation.

Table I: Outcomes of the OSCE assessments

\begin{tabular}{cccccc}
\hline Week & $\begin{array}{c}\text { Number } \\
\text { of } \\
\text { students } \\
\text { engaging }\end{array}$ & $\begin{array}{c}\text { Number } \\
\text { of staff } \\
\text { employed }\end{array}$ & $\begin{array}{c}\text { Number } \\
\text { of } \\
\text { parallel } \\
\text { streams }\end{array}$ & $\begin{array}{c}\text { Number } \\
\text { of } \\
\text { technical } \\
\text { issues } \\
\text { reported }\end{array}$ & $\begin{array}{c}\text { Number } \\
\text { of } \\
\text { students } \\
\text { passing }\end{array}$ \\
\hline 24 & 152 & 60 & 7 & 6 & $\begin{array}{c}127 \\
(83.6 \%)\end{array}$ \\
\hline 26 & 31 & 26 & 3 & 3 & 27 \\
\hline 28 & 4 & 11 & 1 & 0 & 3 \\
\hline
\end{tabular}

Discussion: Extensive planning and preparation with staff and students ensured smooth delivery of OSCEs with minimal technical issues. This format will be considered as part of a blended approach moving forwards.

\section{Reference}

Kakadia, R., Chen, E., Ohyama, H. (2020) Implementing an online OSCE during the COVID-19 pandemic. Journal of Dental Education, 85 (Suppl 1), 1-3. https://doi.org/10.1002/jdd.12323

\section{An evaluation of online clinical pharmacy placements for Master of Pharmacy undergraduates}

Jennifer Silverthorne ${ }^{1^{*}(D)}$, Holly Devine ${ }^{2}$, Kate Oates ${ }^{3}$, Diane Mitchell $^{3}$, Caroline Barrett ${ }^{3}$, Alison Fryer ${ }^{2}$, Daniel Jones ${ }^{3}$

${ }^{1}$ The University of Manchester, United Kingdom

${ }^{2}$ Northern Care Alliance NHS Foundation Trust, United Kingdom

${ }^{3}$ Manchester University NHS Foundation Trust, United Kingdom

*Presenting author: Jennifer.silverthorne@manchester.ac.uk

Keywords: Experiential learning, Pharmacy education, Web-based learning

Background: During the global coronavirus pandemic, some placements for healthcare undergraduates were halted and replaced with online experiences (Daftary et al., 2020; Roskvist et al., 2020; Salter et al., 2020). At one university, hospital pharmacy tutors developed a series of online events to address placement intended learning outcomes (ILOs). Topics covered during 13 small-group placements for years 
two-four included therapeutics e.g. respiratory and diabetes, and clinical skills e.g. clinical checking.

Aim: To evaluate students' perceptions of online clinical pharmacy placements. Objectives included exploring perceptions of the benefits and disadvantages and factors influencing student experiences.

Method: An online survey was developed using closed, Likert scale and open question types. Topics explored were relevant to the delivery of all placements and included learning experiences, tutor support and technological issues. A participant information sheet was emailed to undergraduates in years two-four before the survey was released via the university's virtual learning environment. Students had six weeks to respond, with an email reminder sent after four weeks. The survey was anonymous and evaluated a teaching intervention as such ethical approval was not required.

Results: Sixty-six students completed the survey (overall response rate $14.6 \%) ; 16$ students were from year two, 20 from year three, 30 from year four and the majority of respondents were female $(76 \%, n=50)$. Statistical analysis (Mann-Whitney $U$ test) revealed no significant differences between student responses according to year group or gender. The majority of students agreed that online placements met their ILOs $(78 \%, n=49)$ and were satisfied with placement tutor support $(95 \%, n=60)$. However, around a third $(35 \%, n=22)$ thought that online placements did not adequately replicate in-person placements. Most students (79\%, $n=52$ ) experienced technological problems sometimes or often, with $36 \%$ (24) reporting a resultant adverse effect on their learning experience.

Discussion: Limitations include the low overall response rate, which limits the generalisability of the findings. This study confirms that online placements permitted successful delivery of ILOs related to therapeutics and clinical skills. However, they were not wholly effective in replicating inperson placements, it was not possible to simulate the clinical environment nor interactions with patients and the multidisciplinary team. Students frequently encountered technological problems which were a barrier to learning; universities must consider this when planning blended learning delivery.

\section{Reference}

Daftary, M.N., Jorden, J., Habib, M., Pather, I., \& Tofade, T. (2020). Implementing virtual experiences and remote assessments during the COVID-19 pandemic: A college experience. Pharmacy Education, 20 (2), 54 - 55. https://doi.org/10.46542/pe.2020.202.5455

Roskvist. R., Eggleton. K., \& Goodyear-Smith, F. (2020). Provision of e-learning programmes to replace undergraduate medical students' clinical general practice attachments during COVID-19 stand-down. Education for Primary Care, 31 (4), 247-254. https://doi.org/10.1080/14739879.2020.1772123
Salter, C., Oates, R.K., Swanson, C., \& Bourke, L. (2020). Working Remotely: Innovative Allied Health Placements in Response to COVID-19. International Journal of Work-Integrated Learning, 21 (5), 587-600. https://files.eric.ed.gov/fulltext/EJ1271186.pdf

\section{Pharmacy undergraduates' concerns around attending hospital placements during the coronavirus pandemic}

Jennifer Silverthorne ${ }^{1 *}$ (D) , Holly Devine ${ }^{2}$, Kate Oates ${ }^{3}$, Diane Mitchell ${ }^{3}$, Caroline Barrett ${ }^{3}$, Alison Fryer ${ }^{2}$, Daniel Jones ${ }^{3}$

${ }^{1}$ The University of Manchester, United Kingdom

${ }^{2}$ Northern Care Alliance NHS Foundation Trust, United Kingdom

${ }^{3}$ Manchester University NHS Foundation Trust, United Kingdom

*Presenting author: Jennifer.silverthorne@manchester.ac.uk

Keywords: Experiential learning, Pharmacy education

Background: During the coronavirus pandemic, pharmacy undergraduate hospital placements at one university were rationalised due to capacity problems and local levels of infection. Placements focussing on consultation skills were eventually delivered for years two-four. Research in nursing (Swift et al., 2020) suggests that students may have a variety of anxieties about attending placement during the pandemic.

Aim: To evaluate students' opinions on attending hospital placements during the coronavirus pandemic. Objectives included exploring concerns and factors influencing student opinions.

Method: An online survey was prepared before placements were delivered, using closed, Likert scale and open questions. Topics explored included travel arrangements, infection control and induction requirements as well as possible influencing factors such as COVID-19 mortality risk (e.g. ethnicity, long-term conditions) and home circumstances (e.g. living with vulnerable relatives). A participant information sheet was emailed before the survey was released via the university's virtual learning environment. All students had six weeks to complete the survey, with an email reminder sent after four weeks. The survey was anonymous and explored a teaching intervention; as such, ethical approval was not required by the university. Data were analysed using simple descriptive statistics, and chi squared tests used to determine relationships between variables.

Results: Eighty-two students completed the survey (response rate $13.2 \%$ ). Of these, $71 \%$ (58) were of non-white ethnicity and all had low COVID-19 risk scores. Although none had 
caring responsibilities, 32\% (26) lived with family. More than half $(55 \%, n=45)$ were worried about being exposed to coronavirus on placement, with $38 \%$ (31) concerned about the health of those they lived with. Furthermore, 29\% (24) students were concerned about using public transport, although the majority $(74 \%, n=61)$ were confident wearing personal protective equipment (PPE). There was no statistical association between placement concerns and student ethnicity or living with family.

Discussion: Limitations of this study include the low response rate, which limits generalisability. Findings confirm many students had concerns about their health and those they lived with. Placement tutors provided reassurance via induction elearning, access to PPE, vaccination and lateral flow testing. Placement providers should be mindful of student concerns, taking travelling and home circumstances into account when planning future placements.

\section{Reference}

Swift, A., Banks, L., Baleswaran, A., Cooke, N., Little, C., McGrath, L., Meechan-Rogers, R., Neve, A., Rees, H., Tomlinson, A., \& Williams, G. COVID-19 and student nurses: A view from England. Journal of Clinical Nursing, 29, 3111-3114. https://doi.org/10.1111/jocn.15298

\section{Adapted experiential learning for pharmacy undergraduates: Developed as a result of the COVID-19 pandemic}

\author{
N. Soni*, O. Tsaponia, S. Heasmanm*, J. Portlock \\ University of Sussex, Brighton, United Kingdom \\ *Presenting author: ns493@sussex.ac.uk; \\ S.A.Heasman@sussex.ac.uk
}

Keywords: COVID-19, Medicines reconciliation, Pharmacy education, Simulation learning, Virtual placement

Background: The provision of experiential learning for pharmacy undergraduates is stipulated by the General Pharmaceutical Council (GPhC, 2011); the pandemic resulted in the need to transform in-person placements into virtual alternatives.

Aim: Adapting in-person experiential placements into virtual alternatives.

Objective: Constructing a meaningful virtual experiential placement experience.

Method: A zoom virtual placement week for third and fourthyear students (21 and 25 students) was split into community and hospital pharmacy workshops. The content was created to ensure that the learning outcomes from in-person placements were met. The authors focused on two of these: completing medicines reconciliations and creating casebased discussions (CBDs). This was achieved through a mixture of student-engagement tools and immersive virtual reality (VR) technology. These technologies were utilised to create virtual patients and a ward simulation (WS). Questionnaires were administered to collect the students' feedback on their experiences of the specific activities.

Results: The third-year students found the WS and "live" patient-facing workshops to be the most enjoyable activities. Fourth-year students found CBDs, WS, and complex patient cases to be the most enjoyable. Enjoyability was determined by students ranking activities as the most to the least enjoyable. Improvement ideas included: improved accessibility of the simulated environment, smaller groups for the WS exercise, better organisation of online material, and fewer sessions in one day. $100 \%$ of the third year students learned something new from the WS, compared with $50 \%$ of the fourth-year students.

Discussion: The sessions that students found most enjoyable relate to the learning outcomes of completing medicines reconciliations and CBDs. However, there appears to be more utility for those in the third year with respect to the ward simulation and learning new skills. Overall, the students have enjoyed the virtual alternative, and the in-person learning outcomes were met.

\section{Reference}

General Pharmaceutical Council (2011). Future pharmacists: Standards for the initial education and training of pharmacists. London: GPhC. Available at: https://www.pharmacyregulation.org/sites/default/files/document/ gphc_future_pharmacists_may_2011.pdf

\section{Staff views of the adapted experiential learning experience for $M$. Pharm. students during the COVID-19 pandemic}

N. Soni*, S. Heasmanm*, J. Portlock

University of Sussex, Brighton, United Kingdom

*Presenting author: ns493@sussex.ac.uk; S.A.Heasman@sussex.ac.uk

Keywords: COVID-19, Immersive virtual, Pharmacy education, Reality technology, Simulation learning, Virtual placement

Background: Due to restrictions imposed by the pandemic, in-person experiential placements as recommended by the 
General Pharmaceutical Council (GPhC, 2011) were not viable. As a result, the in-person experience was transformed into a virtual alternative.

Aim: To establish the academics' experience of the virtual alternative by gathering their experience using a questionnaire.

Method: A zoom virtual placement week was spilt into community and hospital workshops delivered to the third and fourth year M. Pharm. students (21 and 25 students). The workshop content was constructed to ensure the in-person placement learning outcomes were met. Student engagement tools such as immersive virtual reality technology were utilised. The delivering academics' experience was assessed via a questionnaire afterwards (18 participants were invited to complete, of whom 14 completed). This was based on similar questionnaires capturing staff opinions on educational initiatives and empirical questions.

Results: Academics were asked which skills they felt the students had gained during the virtual placement. They reported that the students were able to apply their clinical skills taught during the workshops to scenarios such as drug history taking, medicines reconciliation and also develop their oral presentation skills by means of a case-based discussion. When asked what impact the virtual placement had on the students' pharmacy practice skills, nine out of 14 respondents reported that it had provided the students with the opportunity to develop their confidence in utilising these clinical skills.

Discussion: The overall conclusion from the findings was that the virtual placement experience was an excellent learning tool for the students and gave them some of the practical skills they needed before becoming a pharmacist. Going forward, there is a need to ensure that experiences are provided which reflect more pharmacy sectors.

\section{Reference}

General Pharmaceutical Council (2011). Future pharmacists: Standards for the initial education and training of pharmacists. London: GPhC. Available at: https://www.pharmacyregulation.org/sites/default/files/document/ gphc_future_pharmacists_may_2011.pdf

\section{Redesigning pre-registration training in a COVID world}

Jennifer Thomson*, Hayley Wickens

Health Education England (HEE) School of Pharmacy South, Winchester

*Presenting author: Jennifer.Thomson@hee.nhs.uk

Keywords: Online, Pre-registration, Quality Improvement

Background: Health Education England (HEE) South runs preregistration pharmacist (PRP) training across Thames Valley, Wessex and the South West; the regional events moved online in 2020 due to the pandemic. Feedback from the 2020/21 cohort induction event in August 2020 suggested that trainees felt sessions were not interactive enough, despite local host trusts booking rooms where small groups could interact in a socially distanced manner.

Aim: To redesign the delivery of regional courses to enhance the remote learner experience.

Method: A quality improvement "Plan Do Study Act" model was applied when planning the February 2021 event, with increased group activities and breakout groups planned to replicate the in-person experience; sessions started with icebreakers (e.g. virtual scavenger hunt) to allow for interaction. Key stakeholders (lead education and training pharmacist and chief pharmacists) at PRP trusts were engaged to ensure IT support was available. A further feedback survey was sent to participants.

Results: The results can be seen in Table I.

Table I: Survey results

\begin{tabular}{lcc}
\hline & $\begin{array}{c}\text { August 2020 } \\
\text { \% strongly agree or agree }\end{array}$ & $\begin{array}{c}\text { February 2021 } \\
\text { Survey question }\end{array}$ \\
\hline $\begin{array}{l}\text { It was easy to log } \\
\text { in }\end{array}$ & $100 \%$ & $95 \%$ \\
\hline $\begin{array}{l}\text { Online delivery } \\
\text { worked well }\end{array}$ & $81 \%$ & $94 \%$ \\
\hline $\begin{array}{l}\text { I logged in on my } \\
\text { own device }\end{array}$ & $43 \%$ & $100 \%$ \\
\hline Response rate & $73 \%$ & $63 \%$ \\
\hline
\end{tabular}

Discussion: Use of own devices, ice-breakers and small group work designed into the second event led to increased involvement, and increased participant satisfaction. Regional training may retain many of these online features even as pandemic restrictions lift; these events may be as rewarding as face-to-face teaching with less travel for trainees and facilitators. The increase in trainees logging in on their own 
devices rather than in trust-based groups could be the reason for the small increase in difficulties in logging on.

\section{Development and evaluation of online formative Objective Structured Clinical Examinations (OSCE) for pre-registration trainee pharmacists in the United Kingdom}

H. Wickens ${ }^{1 *}(D)$ J. Thomson, H. Ireland ${ }^{1}(D)$, C. Murphy ${ }^{1,2}$, K. Purbrick Thomson ${ }^{1}$, X. Bray ${ }^{1}$, R. James ${ }^{1}$, M. Miell

${ }^{1}$ School of Pharmacy, Health Education England (HEE) South, Oxford, United Kingdom

2Pharmacy Workforce Development South (PWDS), University Hospitals Bristol NHS Foundation Trust, Bristol, United Kingdom

*Presenting author: hayley.wickens@hee.nhs.uk

Keywords: Assessment, Formative, Online, OSCE, Pre-registration

Background: In-person, formative Objective Structured Clinical Examinations (OSCE) are a feature of pharmacist training and used to demonstrate competency and direct further learning (Haughey and Hare, 2017). The coronavirus pandemic has demanded training adapts, including online delivery, thus ensuring educational opportunities remain and are safe.

Aim: Develop and evaluate online formative OSCEs for 130 pre-registration trainee pharmacists undertaking the Health Education England (HEE) South (UK) programme.

Method: The authors developed online OSCEs, basing the structure of the event on a traditional in-person method and transferring this to the online MS Teams environment. Paperbased resources and mark sheets were replaced with online resources accessed by trainees and assessment grids held on HEE SharePoint servers for assessors. An online training preevent was done for all participants, and training videos were made available. After a successful pilot event, online OSCEs were run over three days in January 2021 live on MS Teams. The OSCEs comprised five clinical scenario stations; medication error, potassium supply, antibiotic stewardship, dyspepsia and threadworm consultation. Trainees rotated through all five 10-minute stations. Three circuits ran concurrently. Trainees had an individualised timetable and helped room access for wellbeing and IT concerns. Trainees and assessors were asked to fill an online feedback questionnaire at the end of the event.

Results: Pass rates for each station ranged from $24 \%$ to $86 \%$. Excellent communication and competency were identified by assessors, as well as detecting clinical and consultation skills requiring improvement. Trainee, actor, and assessor feedback on the online process was positive "All went very smoothly... easier than in person!" (Tutor); "A good experience" (Trainee). Many cited the lack of travel as beneficial "Saved time for everyone and more environmentally friendly" (Trainee); "Travelling somewhere unfamiliar... would add stress and cost" (Trainee). Over 60\% of trainees said they would accept OSCEs online again.

Discussion: Online OSCEs were a successful formative assessment. Feedback suggests value in continuing with the online delivery post-pandemic.

\section{References}

Haughey, S., \& O'Hare, R. (2018). Pharmacy OSCEs and competencybased assessments. Edinburgh: Elsevier Health Sciences

\section{Shared learning event evaluation within East Sussex multisector pharmacist programme}

Alice Conway*, Sarah Purdy

Pharmacy East Sussex Healthcare NHS Trust, United Kingdom

*Presenting author: Alice.Conway@nhs.net

Keywords: Evaluation, Curriculum

Background: The East Sussex multisector pharmacist foundation to advanced vocational training scheme (VTS) programme provides structured work-based training, incorporating clinical governance, research, education and leadership skills. The locally developed curriculum is validated against the Royal Pharmaceutical Society (RPS) professional development frameworks. It was that proposed shared learning events (SLE) can foster peer development and interprofessional learning whilst ensuring programme curriculum coverage for participants working in multiple sectors of practice across primary and secondary care, including acute, mental health, care homes, Clinical commissioning group (CCG) and Primary care networks (PCN).

Aim: To create an SLE programme, Identify priority clinical areas for delivery complicit with the Network Contract Directed Enhanced Service (DES), share sector resources by extending SLE invitations to partner sectors, and evaluate participant satisfaction.

Method: A task and finish group (TFG) was assembled with sector educational leads. RPS frameworks, the DES and several postgraduate syllabi to identify key themes for delivery via an SLE series. SLE participants completed an online satisfaction questionnaire after sessions with a fivepoint Likert scale ( 0 being not useful, five being very useful). Participants identified what they had learnt and how to apply learning. Qualitative comments were thematically analysed. 
Results: TFG agreed SLE content, format and structure, scheduled for a full day, four weekly intervals, clinical themes subdivided into specific topics with flipped learning and casebased discussions (CbD). Participant numbers ranged from eight to sixteen. Virtual delivery increased attendance. Overwhelming positive session evaluation, four common themes identified were: Session relevance to practice, appreciation of attendance opportunity; Networking development sharing of practice; Benefit of focus on solutions to enhance the patient transfer of medication from one sector to another and appreciation of working in different sectors; Benefit of pharmaceutical problem solving through $\mathrm{CbD}$.

Discussion: Themes agreed supported alignment with DES requirements. SLE has strengthened networking and collaboration between sectors with virtual delivery continuing.

\section{References}

East Sussex Multisector Foundation to Advanced (MFtA) Vocational Training Scheme (2020). Available at:

https://www.lasepharmacy.hee.nhs.uk/dyn/_assets/_folder4/found ation-pharmacists-pages/vts/esbtvtsheewebsiteinformation.pdf

Royal Pharmaceutical Society. RPS Foundation Pharmacy Framework (2014). Available at:

https://www.rpharms.com/Portals/0/RPS\%20document\%20library/ Open\%20access/Frameworks/RPS\%20Foundation\%20Pharmacy\%20 Framework.pdf

\section{Professionalism in the pre-registration pharmacist placement: An exploratory stakeholder study \\ Helen Ireland ${ }^{1,2^{*}}$ (D), Rebecca O'Rourke ${ }^{1}$ (D) , Julie Sowter ${ }^{3}$ (D) \\ ${ }^{1}$ University of Leeds, United Kingdom \\ 2 Pharmacy Workforce Development South, Bristol, United Kingdom \\ ${ }^{3}$ University of Bradford, United Kingdom \\ *Presenting author: Helen.ireland1@nhs.net}

Keywords: Patient, Pre-registration, Pharmacy, Professionalism, Trainee, Transformative learning

Background: Interest in professionalism within the United Kingdom's healthcare has increased following reports of poor patient care and the development of patient-facing roles for pharmacists. This has led to questioning how professionalism is developed and assessed during pre-registration training. Aim: This novel study explores the General Pharmaceutical Council (GPhC), service users, pre-registration pharmacist trainees and pre-registration tutors from the South West of England perspectives of professionalism.
Method: An interpretative paradigm approach was adopted, involving one semi-structured interview with members of GPhC staff, a qualitative e-questionnaire to tutors, one focus group with trainees and a separate focus group with service users. Active thematic interpretative analysis was used to identify, evaluate and consider patterns and meaning across all data sets.

Results: Trainees and tutors provided insights into transformative moments that happened during the training year to potentiate professionalism development. The firstmoment being issuing of the title "pre-registration trainee". All groups reported constructive and meaningful interactions with patients in the workplace throughout the placement as aiding professionalism maturation from a 'self-centred student' to becoming an 'outwardly looking and responsible professional'. Trainees and tutors reported becoming a professional was more than doing. Although no tutor reported patients formally provided direct feedback on trainees' professionalism, service users wanted to be involved in the assessment. Tutors indicated the rate of professionalism development might be different across sectors of pharmacy practice, with community pharmacy facilitating faster professionalism maturation.

Discussion: This study proposes the existence of transformative moments and maturation periods during preregistration. This study supports and extends the work by Cruess and authors (2016), regarding Miller's pyramid (1990), by recommending the formal and consistent involvement of patients in how judgements are made on a trainee's achievement of professionalism. Careful planning of training placements to enable different rates of professionalism development in different sectors of pharmacy practice needs to be considered.

\section{References}

Cruess. R.L., Cruess. S.R., \& Steinert, Y. (2016). Amending Miller's Pyramid to Include Professional Identity Formation. Academic Medicine, 91 (2), 180-185.

https://doi.org/10.1097/ACM.0000000000000913

Miller, G.E. (1990). The assessment of clinical skills/competence/performance. Academic Medicine, 65 (9), S63S67. https://doi.org/ 10.1097/00001888-199009000-00045 


\section{Exploring the impact of sepsis e-learnings on knowledge and confidence levels among community pharmacists}

Annie Sellers $^{1 *}$, Ellen Schafheutle ${ }^{2}$, Nirandeep Singh Kaila², Nina Wang Ni Chan ${ }^{2}$, Lesley Grimes ${ }^{1}$

${ }^{1}$ Centre for Pharmacy Postgraduate Education (CPPE)

${ }^{2}$ Division of Pharmacy and Optometry, The University of Manchester, United Kingdom

*Presenting author: annie.sellers@cppe.ac.uk

Keywords: Community pharmacy, Pharmacy quality scheme (PQS), Sepsis learning

Background: The pharmacy quality scheme (PQS) for 2019/2020 included sepsis e-learning (Pharmaceutical Services Negotiating Committee, 2019), developed by the Centre for Pharmacy Postgraduate Education (CPPE) to equip pharmacy professionals to identify signs of sepsis, using the National Early Warning Score (NEWS) (Royal College of Physicians, 2017).

Aim: To investigate the impact of the CPPE sepsis e-learning on community pharmacists' knowledge, perceived ability to recognise sepsis and their confidence to respond appropriately.

Method: A 36 item electronic questionnaire was developed, piloted and circulated via email to 5411 pharmacists who had passed the CPPE sepsis assessment. The questionnaire contained demographic questions and employed Likert-type agreement statements.

Results: The response rate was 3.4\% ( $n=185)$. One-hundredand thirty-two respondents (73.3\%) were female, and the majority registered between 2000 and 2009 (52\%). The most common reason given for completing the learning was because it was part of the PQS requirements (85.4\%). The majority of respondents agreed the learning gave them the necessary knowledge (93\%) and confidence (88.6\%) to recognise the signs of sepsis and that the learning equipped them to respond to sepsis appropriately (94.6\%) and feel confident in this ability (89.2\%). Those who had encountered sepsis prior to undertaking it were significantly more likely $(X 2=4.637 ; p=0.031)$ to agree the learning had been relevant to their practice $(91.8 \%)$ compared to those who had not (77.9\%). Most respondents had not been familiar with any NEWS system prior to completing the learning ( $n=148 ; 80 \%)$, and NEWS2 specifically ( $n=156 ; 84.3 \%)$. Nineteen (10.3\%) respondents indicated that they had used NEWS2 since completing the learning.

Discussion: The majority of respondents indicated that the sepsis learning supported them to recognise and respond to learning in practice; recognising the relevance of learning was influenced by prior sepsis exposure.

\section{References}

Pharmaceutical Services Negotiating Committee (2019). PSNC Briefing 029/19: The Pharmacy Quality Scheme 2019/20. Available at: https://psnc.org.uk/wp-content/uploads/2019/07/PSNCBriefing-029.19-The-Pharmacy-Quality-Scheme-2019-20.pdf

Royal College of Physicians (2017). National Early Warning Score (NEWS)2. Available at:

www.rcplondon.ac.uk/projects/outputs/national-early-warningscore-news-2

\section{Provision of support via drop-in sessions to learners and their educational supervisors on the Interim Foundation Pharmacist Programme (IFPP)}

Nkiruka Umaru*, Sejal Gohil, Katie Reygate, Aurora Diaz Lopez, Anne Cole, Jatinder Saimbi, Shabina Azmi

Health Education England, Interim Foundation Pharmacist Programme

*Presenting author: Nkiruka.umaru@hee.nhs.uk

Keywords: Drop-in sessions, Educational Supervisor, IFPP registrants, Interim Foundation Pharmacist Programme, Provisionally Registered Pharmacists, Supervision

Background: The Interim Foundation Pharmacist Programme (IFPP) was established to support the development and practice of the 2019/20 cohort of pre-registration pharmacists whose typical path to qualification was disrupted by the COVID-19 pandemic (Health Education England (HEE), 2021). As part of the programme, drop-in sessions led by IFPP regional leads were offered to IFPP registrants and educational supervisors to provide support and help them to get the most from the programme.

Aim: To describe the engagement with the sessions and ascertain the most common questions and discussion topics that were supported during the drop-in sessions.

Method: Separate drop-in sessions were held for IFPP learners and educational supervisors. They were advertised via the IFPP newsletter and IFPP regional leads. Lunchtime and evening sessions were offered to provide wider access to the intended audience. Drop-in sessions covered a multitude of topics such as learning needs analysis, e-portfolio, 360degree feedback, completion of the General Pharmaceutical Council's (GPhC) registration exam and general queries.

Results: Nine drop-in sessions were delivered with a total attendance of 70 participants. Four were delivered to IFPP registrants and five to educational leads and supervisors. Common questions and discussions covered learning needs 
analysis (LNA), access to e-portfolio, understanding the different functionalities of the e-portfolio and how to update IFPP registrant's details. Positive feedback was provided by attendees either at the end of sessions or emailed after the session to the regional leaders leading the session.

Discussion: Feedback from attendees was very positive and demonstrated the value of these learning community support sessions (Haresnape et al., 2020). Queries raised at these sessions contributed to the FAQs section of the IFPP website. Feedback from the sessions prompted the creation of quick guides for tools and processes, which initially seemed challenging to navigate on the IFPP. The use of an evaluation form at the end of each session could have generated more detailed feedback.

\section{References}

Haresnape J.M., Aiken, F.J., \& Wynn N.C. (2020). Sharing good practice and encouraging community cohesion online: a programme of tutor-led online events for Open University tutors. Open Learning: The Journal of Open, Distance and e-Learning, 35 (1), 1-23. https://doi.org//10.1080/02680513.2020.1752165

Health Education England (2021). Interim Foundation Pharmacist Programme. Available at: https://www.hee.nhs.uk/ourwork/pharmacy/national-training-offers-pharmacyprofessionals/interim-foundation-pharmacist-programme

\section{Uptake of clinical and educational supervision learning to support the Interim Foundation Pharmacist Programme (IFPP) for 2019/20 cohort of pre-registration}

Nkiruka Umaru*, Sejal Gohil, Katie Reygate, Aurora Diaz Lopez, David Gibson, Jonathan Foster, Helen Silcock

Health Education England, Interim Foundation Pharmacist Programme

*Presenting author: Nkiruka.umaru@hee.nhs.uk

Keywords: Clinical supervisor, Educational supervisor, Interim Foundation Pharmacist Programme, Provisionally registered pharmacists, Supervision

Background: The Interim Foundation Pharmacist Programme (IFPP) was established to support the development and practice of the 2019/20 cohort of pre-registration pharmacists whose typical path to qualification was disrupted by the COVID-19 pandemic (Health Education England (HEE), 2021). Part of the IFPP infrastructure included educational supervision to support those provisionally registered with the General Pharmaceutical Council (GPhC) and in practice. A key recommendation to support the educational supervisor role included participation in a recognised programme of learning such as the HEE pharmacy clinical and educational supervisor core skills module developed by the University of East Anglia, Keele University and De Montfort University.

Aim: To describe relevant demographics of pharmacy professionals who accessed the online HEE pharmacy clinical and educational supervisor core skills module.

Method: Routine data, which included the HEE region, sector of practice and the professional group, was collected upon registration to access the learning module between August 2020 and April 2021. Basic descriptive analysis was applied to the data set. Ethics approval was not required.

Results: A total of 1,118 pharmacy professionals registered for the online supervision module. This included 675 (60\%) pharmacists, 434 (39\%) pharmacy technicians and the other category at $1 \%$. The most common identified practice sector was hospital (864, 77\%). Representation was $\leq 8 \%$ in other sectors of practice, including CPPE (93), Community (79), Primary Care (43), Academia (33) and HEE (6). Figure 1 shows the online supervision module registration by HEE regions.

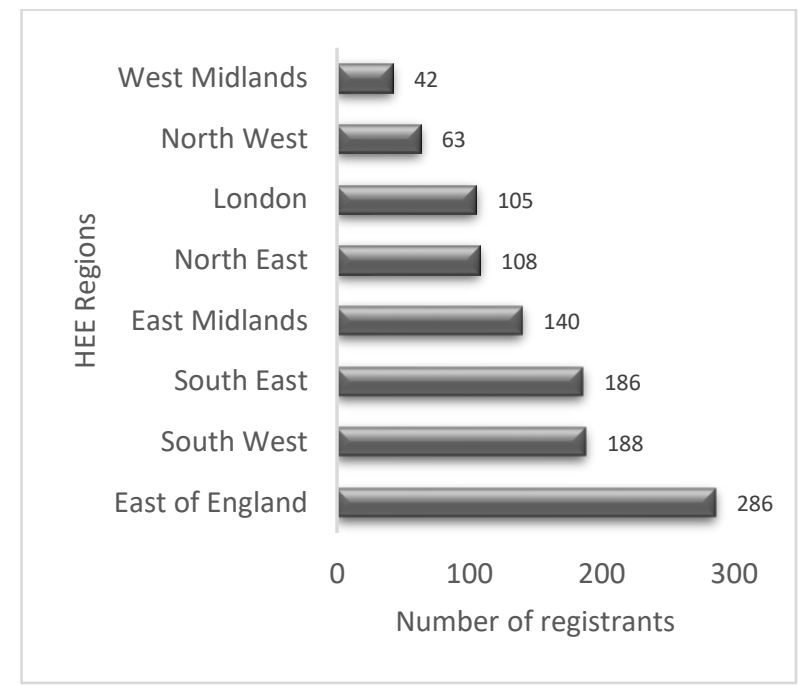

Figure 1: Supervision module registration by HEE region

Discussion: Registration figure suggests that this has been a popular learning resource for pharmacy professionals across sectors. This encourages the development of resources to be used across all pharmacy sectors. The highest uptake was within the hospital sector. The low uptake in other sectors of practice such as Community and CPPE may be explained by the availability and access to similar training resources. The higher number of registrants in the East of England may reflect greater awareness of this resource in the region compared to others.

\section{References}

Health Education England (2021). Interim Foundation Pharmacist Programme. Available at: https://www.hee.nhs.uk/our- 
work/pharmacy/national-training-offers-pharmacyprofessionals/interim-foundation-pharmacist-programme

Health Education England (2020). Educational Supervisor/Tutor Training. Available from:

https://www.hee.nhs.uk/sites/default/files/documents/Overview\% 20SoPMO\%20ES\%20and\%20PS\%20training.pdf

\section{Post-qualification pharmacy students' perception of the Objective Structured Clinical Examination (OSCE)}

Nkiruka Umaru*, Andrzej Kostrzewski

University of Hertfordshire, Hatfield, United Kingdom

*Presenting author: n.e.umaru@herts.ac.uk

Keywords: Assessment, Learning, Objective Structured Clinical Examinations (OSCE), Postgraduate pharmacy, Simulation

Background: Objective Structured Clinical Examination (OSCE) is an established clinical competence assessment used in healthcare professions. Established within the medical profession in the 1970s, non-medical healthcare disciplines have sought to evaluate and affirm its value in training (Kirton et al., 2011). Studies reporting on OSCEs within pharmacy have mainly focused on undergraduate and trainee pharmacist provisions, including an evaluation of the learner's improvement and appraisal alongside other methods. (Aranda et al., 2019). An exploration of OSCEs as an assessment method in the pharmacy post-qualification context is justified to inform development in education and training.

Aim: To explore the use of OSCE as a competency-based assessment strategy in post-qualification pharmacy practice education and training.

Method: Methods were based on an inductive hermeneutic phenomenological research approach (Sloan et al., 2014). Focus group interviews were conducted with students who had experienced OSCEs at a post-qualification level. Invitation to participate was sent through email to 35 students on a postgraduate diploma pharmacy practice programme. Audiorecorded data was transcribed and anonymised. Conventional content analysis was applied to facilitate data analysis and the development of themes. Ethical approval was granted for this study.

Results: Fifteen female students took part in two focus groups lasting for 30 minutes. OSCEs were viewed as a necessary assessment means to endorse clinical skills competency in practice. Failure was reported to have more negative significance due to the professionally registered status of participants. Replicability of real life practice was highly important to participants with suggestions to provide more practice opportunities to enable familiarisation with the OSCE process.

Discussion: Formative OSCEs should be complementary to other learning methods if eventually used summatively for certification purposes. Wellbeing support systems are essential to guide the development of those needing support following an unsuccessful OSCEs outcome. A limitation was the lack of diversity in this study.

\section{References}

Aranda, J.P., Davies, M.L., \& Jackevicius, C.A. (2019). Student pharmacists' performance and perceptions on an evidence-based medicine objective structured clinical examination. Currents in Pharmacy Teaching and Learning, 11, 302-308. https://doi.org/10.1016/j.cptl.2018.12.012

Kirton, S.B., \& Kravitz, L. (2011). Objective Structured Clinical Examinations (OSCEs) compared with traditional assessment methods. American Journal of Pharmaceutical Education, 75 (6), 111. https://doi.org/ 10.5688/ajpe756111

Sloan, A., \& Bowe, B. (2014). Phenomenology and hermeneutic phenomenology: the philosophy, the methodologies and using hermeneutic phenomenology to investigate lecturers' experiences of curriculum design. Quality \& Quantity, 48 (3), 1291-1303. https://doi.org/10.1007/s11135-013-9835-3 